УДК 338.242

\section{E.A. Shchetinina}

\section{THE ATTRIBUTE APPROACH IN MAR- KETING RESEARCHES AND MANAGE- MENT OF COMPETITIVENESS OF SOCIO- ECONOMIC SYSTEMS}

The purpose of the article was to systematize and present the results of the review and the author's clarification of the essence of the attributive method of evaluating system objects for the development of marketing tools, in particular, strategic management of enterprise competitiveness in the conditions of growing turbulence and non-equilibrium of market and other environments. It is proved that the study of the attributive method and the possibilities of its application in strategic management and marketing should be carried out in the framework of a hybrid approach, which is characterized by a combination of different management methods, in particular, qualitative-expert and quantitative-statistical metrics of analysis and evaluation, decision-making with incomplete information. Based on the general theory of systems, the evolutionary approach and taking into account the content of the Kano attribute method, as well as its limited applicability (only for the product), the author made an attempt to distribute the attribution principles to an integral corporate system. The composition of metrics for attributive assessment of a business organization from the point of view of its development stability and competitiveness prospects is justified. A method for evaluating one of the generalizing attribute properties of an organization is proposed. The close connection of the attributive method with branding is emphasized.

Keywords: marketing research, strategic management, competitiveness, attributive method, hybrid approach.

\section{Е.А. Щетинина ${ }^{1}$}

АТРИБУТИВНЫЙ ПОДХОД В МАРКЕТИНГОВЫХ ИССЛЕДОВАНИЯХ И УПРАВЛЕНИИ КОНКУРЕНТОСПОСОБНОСТЬЮ СОЦИАЛЬНО-ЭКОНОМИЧЕСКИХ СИСТЕМ

Целью статьи являлась систематизация и представление результатов рассмотрения и авторского уточнения сущности атрибутивного метода оценки системных объектов для развития маркетингового инструментария, в частности, стратегического управления конкурентоспособностью предприятия в условиях растущей турбулентности и неравномерности рыночной и прочих сред. Доказывается, что исследование атрибутивного метода и возможностей его прикладного применения в стратегическом менеджменте и маркетинге целесообразно вести в рамках гибридного подхода, характерными чертами которого являются сочетание различных методов управления, в частности, качественно-экспертных и количественно-статистических метрик анализа и оценки, принятие решений при неполной информации. Исходя из общей теории систем, эволюционного подхода и учитывая содержание атрибутивного метода Кано, а также ограниченность его применимости (только для товара), автор сделал попытку распространения принципов атрибутивности на целостную - корпоративную - систему. Обоснован состав метрик для атрибутивной оценки бизнес-организации с точки зрения перспектив устойчивости её развития и конкурентоспособности. Предложена методика оценки одного из обобщающих атрибутивных свойств организации. Подчёркнута тесная связь атрибутивного метода с брендингом.

Ключевые слова: маркетинговые исследования, стратегическое управление, конкурентоспособность, атрибутивный подход, гибридный подход.

ВВЕДЕНИЕ. НЫнешняя эпоха изживает многие традиционные подходы и теории как "не работающие" в отношении динамично развивающихся объектов, обуславливая, с одной стороны, рост когнитивности, с другой - эвристическую беспомощность. Причиной

\footnotetext{
${ }^{1}$ Щетинина Е.А., доцент кафедры менеджмента и маркетинга, кандидат экономических наук, доцент; СанктПетербургский государственный технологический институт (технический университет), г. Санкт-Петербург

Shchetinina E.A., Associate Professor of the Department of Management and Marketing, PhD in Economics, Associate Professor; St. Petersburg State Technological Institute (Technical University), St. Petersburg

E-mail: In_77@inbox.ru
} 
последней является повышение неравновесности систем, прежде всего, социо-экологоэкономических. В начале XXI в. наблюдается стойкое нарушение их гомеостаза. И те принципы, положения, модели, фрормулы и категории, которые отражали закономерности движения социально-экономических систем и рынков в прошлом веке, не в состоянии адекватно делать это сегодня. Требуются - как минимум - дополнения, а как максимум существенная модификация методологии и методического арсенала анализа и оценки объектов, которые давали бы возможность прогнозировать их конкурентоспособность и устойчивость в будущем.

Анализ и оценка устойчивости экономических систем выступает ключевой задачей экономики, и если для оценки текущего состояния бизнес-организации (БО) имеются средства в виде методических разработок и ряда подходов, то для прогнозирования и обеспечения будущего компаний такого аппарата явно недостаточно. Пытаясь объяснить проблему, учёные и специалисты связывают данный факт с неизбежностью информационной парадигмы, с экономикой знаний [2], и это верно: связь здесь очевидна. Но причинно-следственные связи таковы, что беспомощность рецептов экономической теории и маркетинга как её ответвления вытекает из отсутствия гомеостаза в системах. Образно говоря, в таких системах невозможно "всё свести к нулю", как требуют принципы бухгалтерии и прочих балансовых методов. Так, например, пяти- или семифакторная модель Альтмана [19] уже не способна оценить риски в условиях неравновесной системы. Иными словами, баланс разнодействующих факторов или потоков недостижим в принципе. И, строго говоря, оттоки и притоки невозможно свести к нулю. Что это значит? Это значит, что возникли новые мерности, новые силы, в том числе, энтропийного характера, не поддающиеся квалиметрическому учёту, и по этой причине функционал управления не способен с необходимой точностью рассчитать траекторию движения социальноэкономической системы (объекта) во времени.

МЕТОДОЛОГИЯ. Обозначенная проблема состоит даже не в многокритериальности задач, стоящих перед менеджментом организации. Дело в том, что практически невозможно дать им, организациям, внятную ключевую метрическую оценку и - соответственно - планировать вероятное положение и метрики её будущего развития. А именно это выступает целью управления, особенно стратегического. Решение проблемы кроется, по мнению автора, в развитии системно-эволюционной методологии [7], [15], гибридного и, в том числе, атрибутивного подхода к рассмотрению и оценке поведения и сущностных характеристик социально-экономических систем, выступающих необходимым условием их будущей продуктивности и рыночной устойчивости. В этой же методологической плоскости находится когнитивное моделирование и его разновидности [9], [16].

ОСНОВНАЯ ЧАСТЬ. Вспомним общеизвестные аксиомы. Высокая конкурентоспособность фирмы является гарантом получения высокой прибыли в рыночных условиях. При этом фирма имеет цель достичь такого уровня конкурентоспособности, а равно прибыльности, который помогал бы ей быть устойчивой, выживать на достаточно долгом временном отрезке, имея возможности своевременной инновационной "мутации", а значит, эволюционирования. В связи с этим перед любой организацией стоит проблема стратегического и тактического управления развитием способности предприятия выживать в изменяющихся условиях [3].

В основе конкурентоспособности предприятия лежит конкурентоспособность его изделий - этот постулат экономической теории никто не отменял. Но эта способность определяется столь многими факторами и условиями, что просчитать их становится нереальной задачей. Поэтому возникает мнение о неспособности маркетинга решить эту задачу, об исчерпании методологии количественных оценок, появляется понятие гибридного подхода к эконометрике, экономическому анализу. Сущность такого подхода трактуется по-разному в зависимости от сферы действия или приложения. Но самая основная черта гибридного метода - паллиативность, половинчатость, в частности, неокончательность решений, полузанятость, полуколичественность, полудоступность, переменное участие (в проекте, процессе, команде), признание изменчивости объекта. Гибридный метод предполагает следование следующим принципам:

экономическая ценность при разумных рисках, что может отменить проект на каком-то из этапов; клиент (или его представитель) должен получать наглядное подтверждение соответствия продукта проекту и его требованиям; разумная гибкость требований, постоянное согласование; ритмичный процесс и постоянная коммуникация; адекватная децентрализация принятия решений: все решения, которые могут быть делегированы отдельным членам команды, должны быть делегированы. 
Таким образом, гибридность в данном контексте направлена на то, чтобы усилить плюсы всех имеющихся методов и компенсировать их недостатки, предлагается сбалансированный набор методов, инструментов и практик. Атрибутивный подход лежит в русле гибридного, дополняя классические инструменты оценки фирмы по данным бухгалтерского отчёта другими инструментами. Рассмотрим его сущность. Как известно, атрибут - необходимое, существенное, неотъемлемое, устойчивое свойство объекта, системы или явления в отличие от случайных, преходящих его состояний. С научной точки зрения атрибут - это абстракция одной характеристики, которой обладают все абстрагируемые как объект сущности, иллюстрируя сущность-связь [8. С. 17].

Если задача стратегического управления состоит в том, чтобы описать траекторию движения системы/объекта во времени и на конкретном рынке, опираясь на её наиболее устойчивые параметры, то речь идёт о том, чтобы для целей такой модели, оценки, прогноза выделить некий ключевой атрибут системы, обладающий указанными выше качествами, который:

является системообразующим;

закономерно связан с сущностью объекта исследования (управления); может быть обеспечен в перспективе;

поддаётся метрическим оценкам;

благодаря которому у системы есть высокая вероятность сохранения и развития в будущем.

И это можно назвать первым этапом атрибутивной оценки БО с точки зрения её устойчивости и стратегической конкурентоспособности на рынке.

Рынок же, как некое поле действий объекта, в свою очередь, находится внутри более крупной системы - социума, неразрывно связанного с природной средой. Атрибуты БО, таким образом, направлены на эту двойную среду - иначе её существование теряет смысл. устойчивым?

Второй вопрос (второй этап), как сфрормировать такой атрибут и сделать его

Здесь необходимо вернуться к сущности атрибутивности. Для этого обратимся к понятию системы и основным положениям теории систем, прежде всего, к работам П.К. Анохина [1].

В противовес многим теоретикам системного подхода - Месаровичу, Раппопорту, Юдину, строившим математические модели систем исходя из их трактовки как "взаимодействия элементов", П.К. Анохин доказывает, что результат системы играет роль системообразующего фактора, включая так называемый "рефлекс цели". Именно результат говорит о качестве системы, а изменение результата - о её способности реагировать на отклонения от цели, перестраиваясь, корректируя своё поведение, находя новые возможности или же - в случае стойкого отрицательного результата - гибнуть или поглощаться более сильным организмом. И мы с необходимостью должны учесть это положение теории систем при формировании комплекса рекомендаций для маркетингового управления БО и её стратегией, в частности, точной постановки целей, стимулирующих рост мотивации, производительности, удовлетворённости трудом и т.п.

Обобщение положений теории функциональных систем позволяет сделать вывод о том, что устойчивость и эффективность системы сводится к таким её способностям, как:

- оценка и контакт-согласование результатов на всех уровнях системной иерархии;

достаточно быстрый перебор-поиск тех механизмов, которые приводят к "чистке" системы от излишних степеней свободы для её элементов, к взаимосодействию и высочайшей интегративности элементов в получении полезного результата.

Эти логические соображения приводят нас к необходимости нахождения такого атрибутивного свойства системы, которое является сущностным, обеспечивая органическую целостность и сохранение главных элементов организации, и в то же время инновативным, позволяющим ей эволюционировать, следуя наиболее перспективным трендам и направлениям науки и практики, например, бионике, генной инженерии, цифровой и наноэкономике, гуманизации бизнеса и пр.

Согласно атрибутивному подходу, источник инфрормации (здесь, корпорация, БО) должен обладать ею, как источник знания - знанием, источник воды - водой, источник фринансов - финансами. Иными словами, в любом источнике информации должна внутренне присутствовать информация, чтобы быть проявленной в сообщениях о себе - с целью достижения своей миссии и планов. Учтём, что любой объект, отражаясь вовне - в нашем сознании, может внутренне самоотражаться в своих свойствах через внутриобъектные информационные процессы. Так, глубинный атрибут мира, именуемый "инфрорма- 
цией", был присущ ему и до человека. Если рассматривать информацию как атрибут природы, то скрытую информацию, хранимую в её информационном поле памяти, можно назвать внутренней (связанной или инсайдерской) информацией в отличие от внешней (свободной) информации, наблюдаемой явно в виде частичного проявления внутренней информации. Но внешняя информация - не копия внутренней, инсайдерской, а лишь её частичное проявление, ограниченное свойствами потребителей, партнёров, а также помехами-шумами со стороны среды, "эффректом наблюдателя" и др.

Исходя из изложенного, внутренняя информация атрибутивна, а внешняя - функциональна. И это методологически важно. Функциональный подход более традиционен и ориентирован только на явную внешнюю инфрормацию, используемую в современной информатике. Атрибутивный подход нетрадиционен, так как ориентирован на скрытую внутреннюю информацию, пока ещё чуждую современной инфооратике. Тем не менее, экономическая информатика вынуждена будет использовать обобщённую (функциональноатрибутивную) информацию в своих задачах.

Это ещё раз убеждает нас в том, что атрибутивный подход - в меру понимания соотношения внутренней информации и внешней - целесообразен в маркетинговых исследованиях, связанных с оценкой конкурентной позиции и собственно конкурентоспособностью и её планированием. Ключевые компетенции БО, по сути, должны отражать атрибутивные свойства её как сложной социально-экономической, биотехнической системы.

Итак, конкурентоспособность (КС), её обеспечение в настоящем и сохранение в будущем - центральная, в высшей степени комплексная задача стратегического менеджмента и маркетинга фирмы [10]. К настоящему времени определены основные параметры КС, связанные с рынком и рыночной позицией, ценовыми и неценовыми преимуществами в виде масштаба производства, марки, сервиса, репутации и имиджа, инновационности и т.д. Стратегии развития БО традиционно направлены на поддержание сильных сторон и укрепление слабых, что может выражаться в технологии, мощностях, поставках, номенклатуре, сервисе, управлении качеством [12]. Но указанные параметры конкуренции - цена, широта ассортимента, уровень стандарта, фирменный кредит не есть атрибуты организации, хотя и выступают проявленным вовне результатом того или иного атрибутивного свойства, а точнее, их совокупности.

Обычно параметры КС делят на три группы: а) технико-экономические; б) коммерческие; в) нормативно-правовые [4].

Но вышеприведённые рассуждения убеждают нас в том, что этого разреза недостаточно, чтобы исследовать глубинные основы КС и обеспечивать её в длительном периоде. Нам важно определить связь внешних параметров КС с атрибутивностью. И здесь важную роль играет отражение информации об атрибутах во внутренней и внешней среде.

Для уточнения атрибутивных свойств вспомним имманентные свойства систем: открытость, эмерджентность, самоорганизация, адаптивность, комбинаторность, синергизм. Если говорить о социальных системах, то следует добавить отношение к процессам, этику, креативность, саморазвитие. Для бизнес-систем это ещё и связь с рынком, соответствие потребностям, ответственность. Но важно обратить внимание на те внутренние свойства БО, которые обеспечивают её гомеостаз - в переводе в древнегреческого "стояние; неподвижность" - свойство организма сохранять относительное динамичное постоянство внутренней среды, качественного состава, устойчивости основных функций и параметров.

Иными словами, это саморегуляция, способность открытой системы сохранять постоянство своего внутреннего состояния и поддержание динамического равновесия, самовопроизводства, преодоления сопротивления внешней среды, адекватного ответа на её вызовы.

Экономический гомеостаз - эволюционно выработанное, традиционно и организационно закреплённое адаптационное свойство социально-экономического организма к условиям и фракторам среды - рыночной и фризической. Но эти условия могут кратковременно или длительно выходить за пределы нормы. В таких случаях адаптация характеризуется не только восстановлением обычных свойств внутренней среды, но и изменениями функций - саморегуляцией в фрорме новаций, изменения числа элементов, ростом экономичности и т.п. Реакции гомеостаза направлены на:

поддержание известных уровней стабильного состояния;

устранение или ограничение действия негативных, вредоносных факторов; выработку и сохранение оптимальных форм взаимодействия организма и среды, а также внутреннего взаимодействия в изменившихся условиях существования. 
Основные компоненты гомеостаза БО были определены нами, отталкиваясь от классификации К. Бернара, и их можно разделить на три группы (Рис. 1).

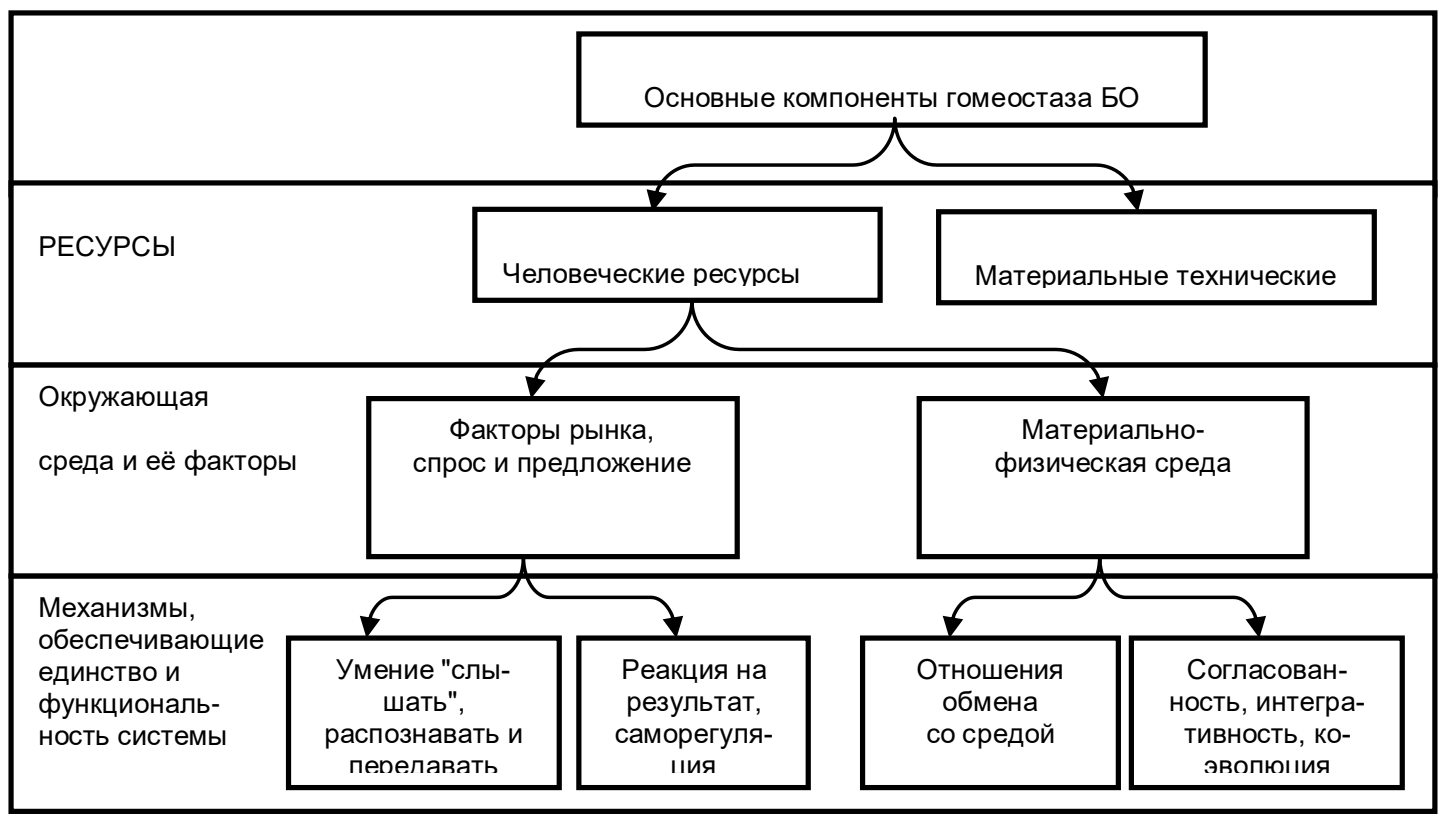

Рис. 1 - Основные компоненты гомеостаза бизнес-организации

Реакции гомеостаза возможны за счёт коллективизма, сознательности, проявляемой в отношениях, ноосферной креативности и внутренней интеграции.

Исходя из этого, атрибутивные качества БО, на наш взгляд, можно определить как:

- умение "слышать" своих потребителей, партнёров, сигналы среды;

- закреплять положительные изменения (механизм запоминания);

- глубинная мотивация персонала;

- непрерывное самообучение;

- использование коллективной памяти, интегративность мышления;

- контакт-координация результатов на всех уровнях системы;

- готовность к переменам.

Обратим внимание, что все эти свойства опираются на человеческие ресурсы, обусловлены ими, их качествами и отношениями.

Выше уже было отмечено, насколько важно иметь в виду влияние результата на работников. Его интерпретация, характер - должны быть учтены при постановке целей организации, обуславливая смысл деятельности всей системы и не сводя его только к финансовым результатам или цели руководства. Поэтому указанные атрибутивные качества вместе с системообразующим фактором результативности можно агрегировать в обобщающий параметр, а именно: целеполагание - умение запрограммировать точный и удовлетворяющий как можно большее число элементов системы результат (цель).

Соответственно, в отношении той или иной конкретной БО нас интересует модель зависимости функциональности (производительности/продуктивности/рентабельности/устойчивости) системы от наличия атрибутов, например, уровня удовлетворённости персонала фрирмы результатом труда, деятельности всей корпорации. Для подобного исследования следует выбирать представителей различных иерархических уровней системы БО.

Методический подход к атрибутивной оценке БО использует структурноморфологический подход, уточнённый В. Титовым [14], атрибутивный метод Н. Кано (1982), принцип "морфологического ящика" Ф. Цвики, принцип Парето, метод экспертных оценок. Использование данного метода в маркетинговых исследованиях предполагает создание списка возможных атрибутов БО и основано на следующих предположениях:

а) если обеспечены атрибуты, соответствующие базовому уровню ожиданий (персонала или потребителя), то восторга это не вызывает, но их отсутствие может повлечь за собой негативную реакцию; 
б) если атрибут соответствует базовому уровню ожиданий, можно утверждать, что его удовлетворённость будет расти по мере улучшения соответствующего атрибутивного свойства объекта.

Если мы рассматриваем внешнюю оценку, то добавляются:

- атрибуты, о которых потребитель не предполагает, но которые будут им высоко оценены, улучшая тем самым их восприятие товара/фирмы в целом.

Респонденты независимо ранжируют свои предпочтения/отторжения. На основании оценок каждый параметр затем относим к одному из классов-категорий. В совокупности эти классы образуют систему координат "УдовлетворённостьФункциональность". Для каждого атрибута БО фрормируется дихотомическая пара вопросов в отношении реакции опрашиваемых:

Позитивный: Если атрибут N присутствует, как Вы к этому отнесётесь?

Негативный: Если атрибут N отсутствует, как Вы к этому отнесётесь?

Как видим, вопросы носят гипотетический характер.

Ответ респондента может соответствовать одному из пяти вариантов: 1) "мне это нравится" - желательный (W); 2) "это абсолютно необходимо" - необходимый (N); 3) "для меня это не имеет значения" - линейный $(\mathrm{L}) ; 4)$ "я это спокойно воспринимаю" безразличный (I); 5) "меня это не устраивает" - обратная зависимость (R).

Далее следует оценить фактический уровень того или иного атрибута, например, удовлетворённость персонала целеполаганием, мотивацией, атмосферой в коллективе и др.

Оценка такого атрибутивного корпоративного качества как "Целеполагание" (обозначим его как атрибут X) по предложенному методу проводилась на примере ООО "Ленэнерго".

В отношении атрибута X варианты вопросов с учётом концепции социальноэтического бизнеса [6] выглядели так:

А) "Если в постановке цели вашей корпорации не учтены цели общества, как Вы к этому отнесётесь?"

Б) "Если в постановке целей вашей корпорации не учтены ваши интересы, как Вы к этому отнесётесь?"

Для оценки доверительных интервалов была использована формула (1):

$\mathrm{N}=z 2 p q N[(N-1) * E 2]+(Z 2 p q)$

где: $\mathrm{N}$ - численность, р - доверительный интервал (95 \%), Z = 1,96 , q- вероятность ошибки (5\%).

Были выбраны три группы опрашиваемых (число сотрудников/число участников соответственно): руководители 10/10; административный персонал 30/28; рабочие 50/45. Итого: 90/82.

Руководители:

$n=1,962(0,5)(0,5) 10[(10-1) * 0,52]+(1,962(0,5)(0,5))$

Административный персонал:

$n=1,962(0,5)(0,5) 30[(30-1) * 0,52]+(1,962(0,5)(0,5))$

Рабочие:

$n=1,962(0,5)(0,5) 50[(50-1) * 0,52]+(1,962(0,5)(0,5))$.

В целом опрошено 82 сотрудника, 92 \% от общей численности.

На 1 этапе была определена степень важности атрибута для персонала.

На 2 этапе - уровень фрактической удовлетворённости целеполаганием по трём выделенным группам. Результаты оценки приведены в Табл. 1.

Таблица 1 - Результаты оценки атрибута X и степени удовлетворённости им на основе опроса персонала

\begin{tabular}{|l|l|l|l|}
\hline \multicolumn{1}{|c|}{ Группы (сегменты) } & \multicolumn{1}{|c|}{ Вариант A } & \multicolumn{1}{|c|}{ Вариант Б } & \multicolumn{1}{|c|}{$\begin{array}{c}\text { Степень } \\
\text { удовлетворённости } \\
\text { атрибутом X }\end{array}$} \\
\hline 1 & \multicolumn{1}{|c|}{2} & \multicolumn{1}{c|}{4} \\
\hline Руководители & $\mathrm{L}(86,1 \%)$ & $\mathrm{W}(74,5 \%)$ & $\begin{array}{l}79,3 \% \\
\text { (высокая степень) }\end{array}$ \\
\hline $\begin{array}{l}\text { Административный } \\
\text { персонал }\end{array}$ & $\mathrm{I}(79,3 \%)$ & $\mathrm{N}(85,9 \%)$ & $\begin{array}{l}60,4 \% \\
\text { (средняя степень) }\end{array}$ \\
\hline Рабочие & $\mathrm{I}(91,6 \%)$ & $\begin{array}{l}18,3 \% \\
\text { (низкая степень) }\end{array}$ \\
\hline
\end{tabular}


По атрибуту X можно сделать вывод, что целеполагание на исследуемом объекте является весьма важным, но при этом его фрактическое состояние не устраивает такой крупный сегмент как "Рабочие".

Таким образом, предложенный методический подход дополняет существующие методы оценки конкурентоспособности и рыночной устойчивости бизнес-организаций (Табл. 2).

Таблица 2 - Основные методы оценки и анализа конкурентоспособности бизнесорганизации

\begin{tabular}{|c|c|c|c|c|c|}
\hline & $\begin{array}{c}\text { Метод сильных } \\
\text { и слабых } \\
\text { сторон }\end{array}$ & $\begin{array}{c}\text { Рейтинговый } \\
\text { метод }\end{array}$ & $\begin{array}{c}\text { Метод, } \\
\text { основанный на } \\
\text { теории } \\
\text { эффективной } \\
\text { конкуренции }\end{array}$ & $\begin{array}{l}\text { Матричный } \\
\text { метод }\end{array}$ & $\begin{array}{l}\text { Атрибутив- } \\
\text { ный метод }\end{array}$ \\
\hline $\begin{array}{l}\text { Авторы, } \\
\text { развивающие } \\
\text { данный подход }\end{array}$ & $\begin{array}{l}\text { Ж. Ламбен, } \\
\text { Е. Голубков } \\
\text { М. Маркин, } \\
\text { И. Роздольская }\end{array}$ & $\begin{array}{l}\text { О. Беленов, } \\
\text { В. Вервейко, } \\
\text { В. Тумин } \\
\text { В. Васильев }\end{array}$ & $\begin{array}{l}\text { И. Костин, Ф. } \\
\text { Хаскиев, } \\
\text { Р. Фатхутдинов } \\
\text { П. Табурчак }\end{array}$ & $\begin{array}{l}\text { МакКинзи, } \\
\text { И. Ансоффф, } \\
\text { Шелл, ВCG }\end{array}$ & $\begin{array}{l}\text { Н. Кано, } \\
\text { А. Русаков } \\
\text { М. Старикова, } \\
\text { Е. Щетинина }\end{array}$ \\
\hline Сущность & \begin{tabular}{lr}
\multicolumn{2}{l}{ Преимущества } \\
и отставание \\
параметров \\
сочетании \\
угрозами \\
возможностями
\end{tabular} & $\begin{array}{l}\text { Оценка в } \\
\text { ряду } \\
\text { конкурентов } \\
\text { по } \\
\text { общеприняты } \\
\text { м } \\
\text { параметрам }\end{array}$ & $\begin{array}{l}\text { Оценка } \\
\text { организации } \\
\text { работы всех } \\
\text { служб } \\
\text { эффективности } \\
\text { ресурсов }\end{array}$ & $\begin{array}{l}\text { Бинарная } \\
\text { оценка } \\
\text { конкурентной } \\
\text { позиции на } \\
\text { рынке }\end{array}$ & $\begin{array}{l}\text { Оценка } \\
\text { атрибутивных, } \\
\text { сущностных } \\
\text { свойств } \\
\text { системы }\end{array}$ \\
\hline Достоинства & $\begin{array}{l}\text { Широкая } \\
\text { область } \\
\text { применения }\end{array}$ & $\begin{array}{l}\text { Ограниченна } \\
\text { я область } \\
\text { применения }\end{array}$ & $\begin{array}{l}\text { Относительно } \\
\text { высокая } \\
\text { объективность }\end{array}$ & Наглядность & $\begin{array}{l}\text { Исследует } \\
\text { глубинные } \\
\text { механизмы } \\
\text { систем } \\
\end{array}$ \\
\hline Недостатки & $\begin{array}{l}\text { Минусы } \\
\text { экспертной } \\
\text { оценки, } \\
\text { субъективность }\end{array}$ & $\begin{array}{l}\text { Ограниченно } \\
\text { е применение }\end{array}$ & $\begin{array}{ll}\text { Не учитывается } \\
\text { отношение } \\
\text { потребителей } \\
\text { перспективы } \\
\text { развития } \\
\text { будущем }\end{array}$ & $\begin{array}{l}\text { Не учитывает } \\
\text { динамики, } \\
\text { фиксируя } \\
\text { текущее } \\
\text { положение }\end{array}$ & $\begin{array}{l}\text { Минусы } \\
\text { экспертной } \\
\text { оценки }\end{array}$ \\
\hline
\end{tabular}

РЕЗУЛЬТАТЫ. Применение системного подхода к анализу и оценке социальноэкономических объектов позволяет выделить два типа системообразующих фракторов внешние или функциональные, и внутренние - изоморфно-атрибутивные. Первые связаны с результатами системы, отношением потребителей к товару и фирме, вторые - с механизмами их обратной связи, восприятия, взаимосодействия субсистем и элементов. Синтез функционального и атрибутивного подходов в оценке социально-экономических систем даёт возможность осуществлять анализ фрирмы как целого - на уровне корпорации, с микроанализом - на уровне субсистем и элементов.

Учитывая актуальность атрибутивных принципов анализа, традиционный перечень вопросов стратегического и конкурентного анализа должен быть расширен, т.е. операционные фракторы, связанные с результатами БО, должны быть дополнены атрибутивными. Оценка атрибутивных свойств носит по определению качественный характер, и этот метод находится ещё в начальной стадии своей разработки, требуя междисциплинарного (маркетинг, менеджмент, социометрия, психология) подхода для своего обоснования и реализации.

В заключение отметим, что атрибутивный подход также однозначно применим к технологиям брендинга, как процесса управления корпоративным брендом, который по определению состоит из атрибутов товара и фирмы. Управление брендом означает, по сути, планомерное фрормирование, закрепление и поддержку атрибутивных характеристик БО (корпорации), которые наиболее значимы для потребителей и общества. В плоскости атрибутивного подхода лежит также HR-брендинг как разновидность брендинга, представляющий собой технологию разработки бренда работодателя, отражающего его имидж, финансовую состоятельность, надёжность, престижность работы в данной организации, её отношение к своему персоналу [9. С. 39].

Итак, маркетинговое управление конкурентоспособностью с учётом атрибутивных методов предполагает разработку совокупности мер, направленных, прежде всего, на укрепление сущностных свойств системы. 


\section{Список использованных источников}

1. Анохин П.К. Принципиальные вопросы общей теории функциональных систем. - М.: Наука, 1973. - 36 с.

2. Баранов Д.Н. Сущность и содержание категории "цифровая экономика" // Вестник Московского ун-та им. С.Ю. Витте. Экономика и управление. - 2018. - № 2. - С. $1-2$.

3. Гибсон Дж.Л. Организации: поведение, структура, процессы. Пер. с англ. - М.: ИНФРА-М, 2000. - $332 \mathrm{c}$.

4. Дубино Н.В., Щетинина Е.Д. Управление конкурентоспособностью предприятия. - Белгород: БГТУ им. В.Г. Шухова, 2016. - 242 с. $312 \mathrm{c}$.

5. Дубровин И.А. Поведение потребителей. 4-е изд. - М.: Дашков и К., 2015. -

6. Кострюкова Я.А., Мигушова Т.О., Сенина Ю.А. Социально-этический маркетинг как инструмент реализации корпоративной социальной ответственности // Торговоэкономический журнал. - 2015. - №. 2(4). - С. 275-284.

7. Нельсон Р., Уилтер С. Эволюционное моделирование. Мировая экономическая мысль. - М.: Мысль, 2004. - С. 484-487.

8. Новейший философский словарь. Под ред. В.А. Кондрашова, Д.А. Чекаева. Ростов-на-Дону, 2008.

9. Осовицкая H.E. HR-брендинг: Работа с поколением Y, новые инструменты для коммуникации, развитие корпоративной культуры и ещё 9 эфрфективных практик. СПб: ПИТЕР, 2015.

10. Полевода С.В. Методические основы маркетингового анализа // Учёт и статистика. - 2015. - № 2(38). - С. 57-63.

11. Попов Е.В. Миниэкономика - приоритетное направление исследований // Вестник РАН. - 2004. - Т. 74. - № 9. - С. 806-812.

12. Пострелова А.В., Маркин М.С. Оценка конкурентоспособности предприятия // Молодой учёный. - 2013. - № 6. - С. 398-402 // URL https://moluch.ru/archive/53/7077/ (дата обращения: 29.02.2020).

13. Сухарев О.С. Экономическая теория эволюции институтов и технологий (проблемы моделирования в эволюционной теории и управлении): Институты и технологии. Институциональное моделирование, структурные модели / О.С. Сухарев. - М.: Ленанд, 2019. - 312 c.

14. Титов В.В. Морфологический подход. - М.: ВИИПИ, 1990.

15. Тхакушинов Э.К. Формирование матрицы атрибутивных оценок риска субъектами управления инвестиционными рисками региона // Международный журнал прикладных и фундаментальных исследований. - 2015. - № 12 (часть 3). - С. 512-515.

16. Ферейра Опасо Е.В., Терелянский П.В. Методика принятия решений по управлению сложной СЭС предприятия на основе объёмного визуального когнитивного моделирования // Современная экономика: проблемы и решения. - ВГУ. - 2019. - №3. C. $108-112$.

17. Donaires O.S., Martinelli D.P. (2019). Evolutionary Management: From Theory to Action // Systems Research and Behavioral Science. - Vol. 36. - PP. 66-86.

18. Festing M., Barzantny C. (2008). A comparative approach to performance management in France and Germany: The impact of the European and the country-specific environment // European Journal of International Management. - Vol. 2. - No. 2. - PP. 208-227.

19. Lubawa G. \& Louangrath P. (2016). Using Altman Z-Score to Assess the Financial Effects of Multiple Loans on SMEs // International Journal of Research \& Methodology in Social Science. - Vol. 2. - No. 1. - PP. 63-86. (Jan. - Mar. 2016). 